\title{
Enhanced proportion of small adipose cells in insulin- resistant vs insulin-sensitive obese individuals implicates impaired adipogenesis
}

\author{
T. McLaughlin • A. Sherman • P. Tsao • O. Gonzalez • \\ G. Yee • C. Lamendola • G. M. Reaven • S. W. Cushman
}

Received: 3 January 2007 / Accepted: 15 February 2007 / Published online: 5 June 2007

(C) Springer-Verlag 2007

\begin{abstract}
Aims/hypothesis The biological mechanism by which obesity predisposes to insulin resistance is unclear. One hypothesis is that larger adipose cells disturb metabolism via increased lipolysis. While studies have demonstrated that cell size increases in proportion to BMI, it has not been clearly shown that adipose cell size, independent of BMI, is associated with insulin resistance. The aim of this study was to test this widely held assumption by comparing adipose cell size distribution in 28 equally obese, otherwise healthy individuals who represented extreme ends of the spectrum of insulin sensitivity, as defined by the modified insulin suppression test.

Subjects and methods Subcutaneous periumbilical adipose tissue biopsy samples were fixed in osmium tetroxide and passed through the Beckman Coulter Multisizer to obtain
\end{abstract}

T. McLaughlin and A. Sherman contributed equally to this study.

Electronic supplementary material The online version of this article (doi:10.1007/s00125-007-0708-y) contains supplementary material, which is available to authorised users.

T. McLaughlin $\cdot$ P. Tsao $\cdot$ O. Gonzalez $\cdot$ G. Yee $\cdot$ C. Lamendola $\cdot$ G. M. Reaven

Department of Medicine, Stanford University School of Medicine, Stanford, CA, USA

A. Sherman · S. W. Cushman

National Institute of Diabetes and Digestive and Kidney Diseases,

National Institutes of Health,

Bethesda, MD, USA

T. McLaughlin ( $\bowtie)$

Division of Endocrinology,

Stanford University School of Medicine,

300 Pasteur Drive, Rm S025,

Stanford, CA 94305-5103 USA,

e-mail: tmclaugh@stanford.edu cell size distributions. Insulin sensitivity was quantified by the modified insulin suppression test. Quantitative real-time PCR for adipose cell differentiation genes was performed for 11 subjects.

Results All individuals exhibited a bimodal cell size distribution. Contrary to expectations, the mean diameter of the larger cells was not significantly different between the insulin-sensitive and insulin-resistant individuals. Moreover, insulin resistance was associated with a higher ratio of small to large cells $(1.66 \pm 1.03$ vs $0.94 \pm 0.50, p=0.01)$. Similar cell size distributions were observed for isolated adipose cells. The real-time PCR results showed two- to threefold lower expression of genes encoding markers of adipose cell differentiation (peroxisome proliferator-activated receptor $\gamma 1$ [PPAR $\gamma 1$ ], PPAR $\gamma 2$, GLUT4, adiponectin, sterol receptor element binding protein 1c) in insulinresistant compared with insulin-sensitive individuals.

Conclusions/interpretation These results suggest that after controlling for obesity, insulin resistance is associated with an expanded population of small adipose cells and decreased expression of differentiation markers, suggesting that impairment in adipose cell differentiation may contribute to obesity-associated insulin resistance.

Keywords Adipocyte - Adiponectin - Adipose cell differentiation - Adipose cell size - Insulin resistance . Obesity Peroxisome proliferator-activated receptor $\gamma$. PPAR $\gamma$

$\begin{array}{ll}\text { Abbreviations } \\ \text { ANCOVA } & \text { analysis of covariance } \\ \text { Ct } & \text { threshold cycle } \\ \text { GLUT4 } & \text { glucose transporter } 4 \\ \text { IST } & \text { insulin suppression test } \\ \text { MANOVA } & \text { multivariate analysis of variance }\end{array}$




$\begin{array}{ll}\text { NIDDK } & \begin{array}{l}\text { National Institute of Digestive Diseases and } \\ \text { Kidney Disease }\end{array} \\ \text { NIH } & \text { National Institutes of Health } \\ \text { PPAR } \gamma & \text { peroxisome proliferator-activated receptor } \gamma \\ \text { SREBP } & \text { sterol receptor element binding protein } \\ \text { SSPG } & \text { steady-state plasma glucose } \\ \text { SSPI } & \text { steady-state plasma insulin } \\ \text { HIV } & \text { human immunodeficiency virus }\end{array}$

\section{Introduction}

Despite all the evidence [1-6] indicating that excess adiposity is associated with the impairment of insulinmediated glucose uptake in muscle, the cellular/metabolic mechanisms that explain how an increase in fat mass leads to this derangement are not clear. The lack of clarity concerning the mechanistic link between increased fat mass and muscle insulin resistance is further compounded by evidence that not all overweight/obese individuals are insulin resistant, and that equally obese individuals can be insulin sensitive, as well as insulin resistant [7-10].

One putative link between obesity and muscle insulin resistance is the manner in which adipose cells expand their fat storage capacity. Studies dating back to the 1970s evaluated adipose cell size with respect to obesity, showing that obese individuals with enlarged subcutaneous abdominal adipose cells are more likely to be hyperinsulinaemic and glucose intolerant than individuals with smaller adipose cells [11-18]. These findings led to the notion that individuals with hypertrophic, as opposed to hyperplastic, obesity were more likely to be insulin resistant and develop diabetes [12].

However, in these studies all adipose cells were counted and total lipid was extracted to determine the average cell size [18]. Furthermore, the majority of studies lacked control subjects matched in terms of BMI, an obvious confounder of the observed associations. Using newer Beckman Coulter (Miami, FL, USA) Multisizer technology and software, we have noted that the adipose tissue of Zucker fatty rats displays a complex distribution of adipose cell sizes, appearing to comprise populations of both small and large cells, such that determination of the average cell diameter does not adequately describe the cell population (D. G. Hunt, X. Chen, M. Santos, N. Tserentsoodol, S. Cushman; unpublished data). Based on these observations, we decided to further investigate the link between adipose cell size and insulin resistance. Our study differs from prior studies in that (1) we quantitated cell size and distribution using Multisizer technology, and (2) our experimental population consisted of moderately obese individuals who were either very insulin resistant or very insulin sensitive, but matched in terms of BMI.

\section{Subjects and methods}

Subjects Participants included 28 overweight or obese individuals, identified during screening for a weight-loss study, who were either insulin resistant or insulin sensitive as quantitated by the insulin suppression test (IST; see below), and who consented to undergo an adipose tissue biopsy. We attempted to match potentially eligible individuals in each group according to BMI and sex. All participants were non-diabetic, as defined by a fasting plasma glucose level of $<7.0 \mathrm{mmol} / \mathrm{l}$, except for one individual who had diet-controlled type 2 diabetes. All were in good general health and were required to have had a stable weight for at least 3 months prior to study entry. None had a history of eating disorders, cardiovascular disease, gastric bypass surgery, liposuction or use of diet (weight loss) medications. The study was approved by the Stanford University Human Subjects Committee and the National Institute of Digestive Diseases and Kidney Disease (NIDDK) Institutional Review Board, and all subjects gave written informed consent.

Quantitation of insulin-mediated glucose disposal Insulinmediated glucose disposal was quantified by a modification [19] of the IST as originally described and validated [20, 21]. Briefly, subjects were infused for $180 \mathrm{~min}$ with octreotide $\left(0.27 \mu \mathrm{g} \mathrm{m}^{-2} \mathrm{~min}^{-1}\right)$ to suppress endogenous insulin secretion, insulin $\left(25 \mathrm{mU} \mathrm{m}^{-2} \mathrm{~min}^{-1}\right)$ and glucose $(240 \mathrm{mg}$ $\mathrm{m}^{-2} \mathrm{~min}^{-1}$ ). Blood was drawn at $10 \mathrm{~min}$ intervals from 150 to $180 \mathrm{~min}$ of the infusion to measure plasma glucose and insulin concentrations, and the mean of the four values for each parameter was used as the steady-state plasma glucose (SSPG) and insulin (SSPI) concentration. As SSPI concentrations are similar in all subjects during these tests, the SSPG concentration provides a direct measure of the ability of insulin to mediate the disposal of an infused glucose load; the higher the SSPG concentration, the more insulin resistant the individual. Based on a prior study of the distribution of SSPG concentrations in 449 healthy non-diabetic adults [22], we defined cut-off values for insulin resistance and sensitivity as those values delineating the top and bottom 40th percentiles of the SSPG distribution, respectively. Only individuals with concentrations above or below these cutoff values were invited to undergo an adipose tissue biopsy.

Plasma glucose, insulin and lipid/lipoprotein concentrations were measured after an overnight fast as described previously [20, 23]. Other experimental measurements included weight; height; BMI, calculated as weight in kilograms/(height in metres) ${ }^{2}$; waist circumference, measured at end-expiration as the point midway between the iliac crest and lower costal margin; aerobic exercise, expressed as $\mathrm{min} /$ week; race/ethnicity; and blood pressure (average of six readings). 
Adipose tissue biopsy and cell size analysis Adipose tissue was obtained under sterile conditions with administration of 0.25 bupivocaine with adrenaline (epinephrine) for local anaesthesia. A $1 \mathrm{~cm}$ scalpel incision was made inferior to the umbilicus, from which $2 \mathrm{~g}$ of subcutaneous adipose tissue was removed. Two samples of $20-30 \mathrm{mg}$ of tissue were immediately fixed in osmium tetroxide and incubated in a water bath at $37^{\circ} \mathrm{C}$ for $48 \mathrm{~h}$ as described previously [14], and then adipose cell size was determined by a Beckman Coulter Multisizer III with a $400 \mu \mathrm{m}$ aperture. The range of cell sizes that can effectively be measured using this aperture is $20-240 \mu \mathrm{m}$. The instrument was set to count 6,000 particles, and the fixed-cell suspension was diluted so that coincident counting was $<10 \%$. After collection of pulse sizes, the data were expressed as particle diameters and displayed as histograms of counts against diameter using linear bins and a linear scale for the $x$-axis.

As an adjunct to the Multisizer analysis, samples of osmium-fixed adipose cells and paraformaldehyde-fixed adipose tissue were viewed by light and scanning electron microscopy using standard laboratory techniques. Photographs were taken and cell size distribution was evaluated using National Institutes of Health (NIH) Image J (available from http://rsb.info.nih.gov/ij/, last accessed in May 2007).

In another test of cell size distribution, adipose tissue biopsy samples from two moderately obese subjects were divided into two and then either fixed directly for cell size analysis or subjected to the collagenase digestion, cell flotation technique [24] for isolation of adipose cells prior to being fixed for cell size analysis. This test compared the cell size distribution of all cells collected from tissue pieces by the osmium fixation procedure ( $25 \mu \mathrm{m}$ nylon filter) with the cell size distribution of cells that were designated as adipose cells on the basis of floatation.

For each participant, analysis of adipose cell size distribution from Multisizer graphs (Fig. 1) entailed identification of the nadir, which was defined as the low point (in frequency) between the two cell populations, i.e. where the curve between the two populations was flat, the midpoint was designated the nadir. The number of adipose cells above and below this point was calculated by the Multisizer software, and expressed as the ' $\%$ above' and ' $\%$ below' the nadir, as well as the ratio of small to large cells. In addition, the 'peak diameter' of the large adipose cells was defined as the mean diameter at which the frequency of the large cell population reached a maximum. Finally, the Multisizer software calculated the mean, median and mode of the overall cell size for each subject.

Quantitative real-time PCR for markers of adipose cell differentiation Total RNA was extracted from flash-frozen adipose tissue biopsies using Trizol (Life Technologies, Gaithersburg, MD, USA) and the Adipose Tissue RNAeasy a

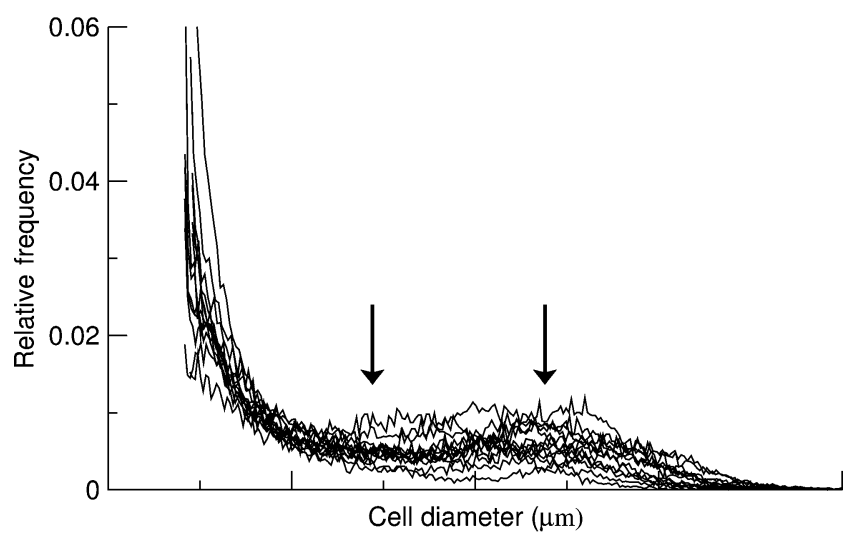

b

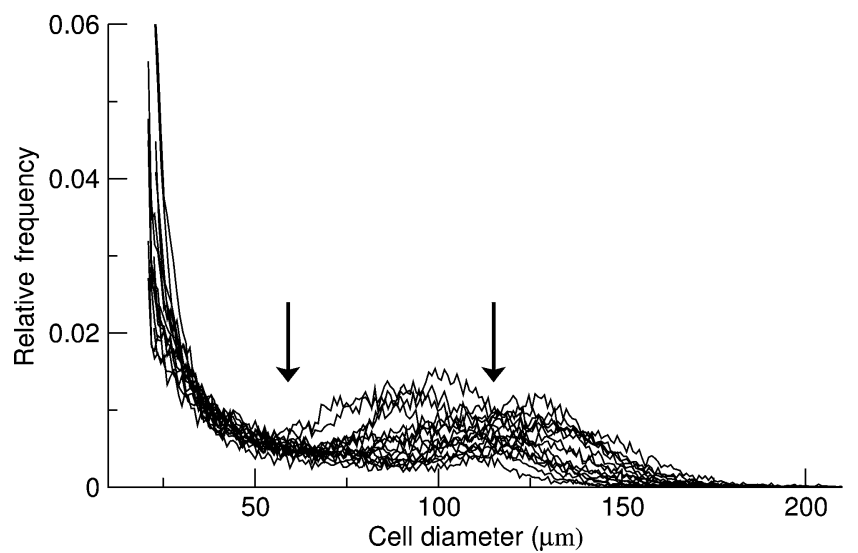

Fig. 1 Multisizer adipose cell profiles of insulin-resistant (a) and insulin-sensitive (b) subjects, plotting cell diameter using linear bins against relative frequency. The AUCs are normalised to 1.0, and the frequency profiles are truncated at $y=0.06$ for clarity. The nadir is the low point (in frequency) between the two cell populations, i.e. where the curve between the two populations was flat, the midpoint was designated the nadir. The peak diameter is the mean diameter of cells above the nadir, or 'large' cells. The arrows indicate the means for the nadir (left) and peak diameter (right) for each group

kit (Qiagen, Valencia, CA, USA) according to the manufacturers' instructions. After DNase treatment, cDNA was synthesised from $5 \mathrm{mg}$ of total RNA using the Maloney murine leukaemia virus reverse transcriptase (SuperScript II kit; Invitrogen, Carlsbad, CA, USA). Taqman primer/probe sets for mRNA transcripts of adipose cell differentiation markers sterol receptor element binding protein $1 \mathrm{c}$ (SREBP1c), peroxisome proliferator-activated receptor $\gamma 1$ (PPAR $\gamma 1$ ), PPAR $\gamma 2$, adiponectin, GLUT4 and adipsin, as well as for $18 \mathrm{~S}$ ribosomal RNA were purchased from Applied Biosystems (Foster City, CA, USA). Amplification was carried out in triplicate on an ABI Prism 7700 sequence detection system at $50^{\circ} \mathrm{C}$ for $2 \mathrm{~min}$ and $95^{\circ} \mathrm{C}$ for $10 \mathrm{~min}$, followed by 40 cycles of $95^{\circ} \mathrm{C}$ for $15 \mathrm{~s}$ and $60^{\circ} \mathrm{C}$ for $1 \mathrm{~min}$. A threshold cycle ( $\mathrm{Ct}$ value) was obtained from each amplification curve and a $\Delta \mathrm{Ct}$ value was first calculated by subtracting the $\mathrm{Ct}$ value for $18 \mathrm{~S}$ ribosomal RNA from the $\mathrm{Ct}$ value for each sample. A $\Delta \Delta \mathrm{Ct}$ value 
was then calculated by subtracting the $\Delta \mathrm{Ct}$ value of a single insulin-sensitive subject (control). Fold changes compared with the control were then determined by calculating $2^{\Delta \Delta \mathrm{Ct}}$.

Statistical analysis Student's unpaired $t$ tests or the $\chi^{2}$ test (for categorical variables) were used to compare the clinical and laboratory characteristics between the two groups and to evaluate the primary endpoints with regard to cell size distribution between the two groups. These endpoints were the nadir, the ratio of small to large cells, and the peak diameter of the population large cells. Potential confounders (sex, BMI or waist circumference, and exercise) were entered into analysis of covariance (ANCOVA) models in which the cell size distribution endpoints were dependent variables and the insulin-resistant group was the primary grouping variable, with Scheffe's adjustment for multiple comparisons. Comparisons of relative gene expression as quantitated by real-time PCR (below) were compared with unpaired Student's $t$ tests. These analyses were performed using Systat 10.0 (SPSS, Chicago, IL, USA).

Further quantitative analyses were carried out via mathematical modelling (non-linear least-squares function nls, R 1.9; available from: http://www.r-project.org, last accessed in May 2007), in which a single formula using seven cell-size parameters could describe the individual data points of each subject:

$$
\begin{aligned}
y= & h_{1} \exp \left(-\left[x-x_{0}\right] / w_{1}\right)+h_{2} \exp \left(-\left[x-x_{0}\right] / w_{2}\right) \\
& +h_{\mathrm{p}} \exp \left(-\left[x-c_{\mathrm{p}}\right]^{2} / w_{\mathrm{p}}\right)
\end{aligned}
$$

where $x=$ cell diameter and $x_{0}=$ the smallest diameter; $h_{1}$ and $w_{1}=$ height and width of the first exponential; $h_{2}$ and $w_{2}=$ height and width of the second exponential; and $h_{\mathrm{p}}, c_{\mathrm{p}}$, and $w_{\mathrm{p}}=$ height, centre and width of the Gaussian curve. In the curve formulated by this equation, the small cells are represented by the sum of two exponentials and the large cells are represented by a Gaussian curve (Electronic supplementary material [ESM] Fig. 1). The composite difference between the curve profiles of the two groups was assessed via multivariate analysis of variance (MANOVA). Between-group differences for each of the seven cell size parameters in the equation were assessed via unpaired Student's $t$ test. For all analyses, a $p$ value equal to or less than 0.05 was considered statistically significant.

\section{Results}

Thirteen insulin-resistant and 15 insulin-sensitive overweight or obese subjects underwent adipose tissue biopsies. The clinical and laboratory characteristics of the two subject groups are shown in Table 1. By selection, the difference in insulin resistance was dramatic, with the mean SSPG in the insulin-resistant subgroup approximately threefold greater than the values in the insulin-sensitive subgroup. Also by selection, the two groups were well-matched in terms of BMI $(30.6 \pm 4.1$ vs $29.4 \pm 2.7)$ and waist circumference (102 \pm 12 vs 989$)$. No statistically significant differences were observed between the groups in terms of age, sex, reported levels of exercise, blood pressure, fasting glucose, or total cholesterol or LDL-cholesterol. Plasma triacylglycerol concentrations were higher and HDL-cholesterol concentrations were lower in the insulin-resistant obese participants.

Table 1 Clinical characteristics and cardiovascular risk markers in insulin-resistant versus insulin-sensitive obese individuals who underwent an adipose cell biopsy

\begin{tabular}{llll}
\hline Variable & Insulin resistant $(n=13)$ & Insulin sensitive $(n=15)$ & $p$ value \\
\hline SSPG (mmol/l) & $12.61 \pm 2.28$ & $4.28 \pm 2.0$ & $<0.001$ \\
Race (white/Asian/Hispanic) & $9 / 3 / 1$ & $13 / 1 / 1$ & 0.14 \\
Sex (female/male) & $9 / 4$ & $11 / 4$ & $54 \pm 9$ \\
Age & $49 \pm 8$ & $29.4 \pm 2.7$ \\
BMI $\left(\mathrm{kg} / \mathrm{m}^{2}\right.$ ) & $30.6 \pm 4.1$ & $98 \pm 9$ & 0.81 \\
Waist circumference (cm) & $102 \pm 12$ & $209 \pm 153$ \\
Exercise (min/week) & $147 \pm 205$ & $123 \pm 17$ \\
Systolic blood pressure (mmHg) & $123 \pm 17$ & $69 \pm 8$ & 0.35 \\
Diastolic blood pressure (mmHg) & $71 \pm 9$ & $5.5 \pm 0.5$ \\
Fasting glucose (mmol/l) & $5.5 \pm 0.83$ & $5.22 \pm 0.78$ \\
Cholesterol (mmol/l) & $5.48 \pm 1.14$ & $1.02 \pm 0.37$ \\
Triacylglycerol (mmol/l) & $2.07 \pm 0.82$ & $1.84 \pm 0.59$ \\
HDL-cholesterol (mmol/l) & $1.24 \pm 0.23$ & $2.95 \pm 0.75$ \\
LDL-cholesterol (mmol/l) & $3.31 \pm 1.24$ & 0.31 \\
\hline
\end{tabular}

Data are presented as means \pm SD

${ }^{\text {a }}$ Student's unpaired $t$ test or $\chi^{2}$ test 
a

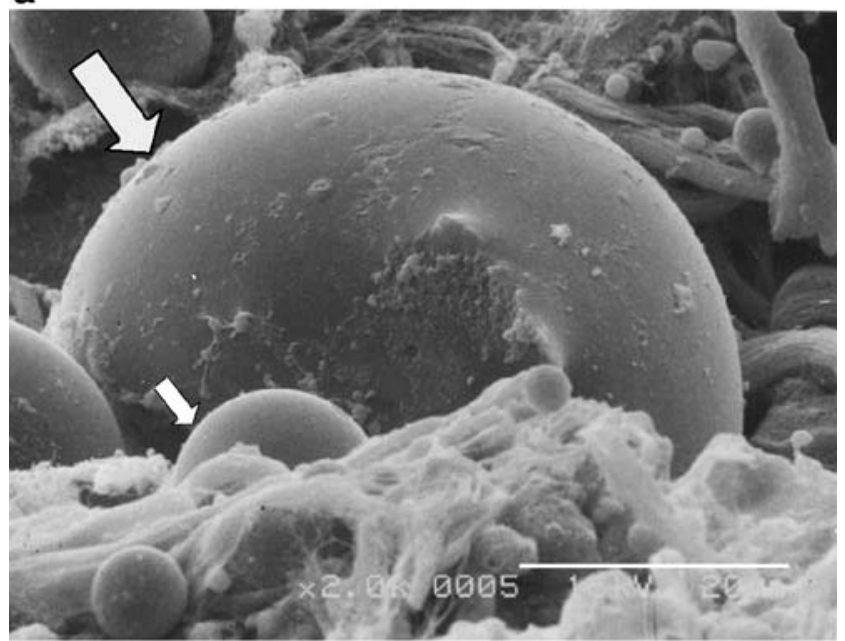

b

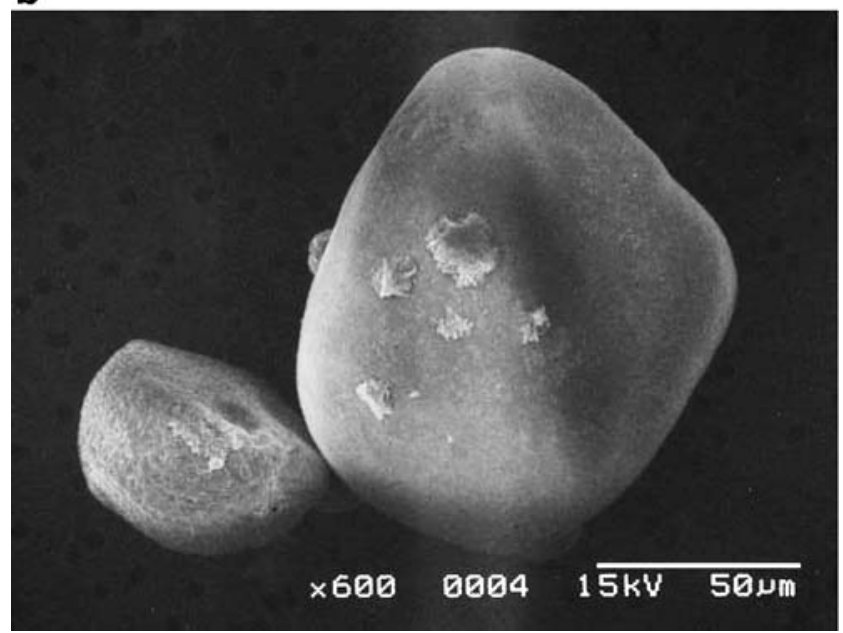

Fig. 2 Photographic examples of human adipose cells of widely varying cell size. a Scanning electron micrograph of paraformaldehyde-fixed tissue, showing small and very small adipose cells (arrows indicate cells of approximately 45 and $10 \mu \mathrm{m}$ diameters). b Scanning electron micrograph of osmium-fixed cells, showing large and small adipose cells

Figure 1 illustrates the adipose cell size distributions of all 28 subjects, as determined by Multisizer analysis using cells isolated from osmium-fixed adipose tissue. The adipose cell distribution was bimodal in every subject as a result of a variable, but generally large, proportion of small cells. That the small cells identified by Multisizer were truly adipose cells is supported by scanning electron microscopy of both paraformaldehyde-fixed tissue and osmium-fixed cells processed for Multisizer analysis, shown in Fig. 2, which clearly demonstrates the presence of small adipose cells, which appear as spherical objects, along with stromal vascular cells (rod-or finger-like cells, Fig. 2a only) and monocytes (very small objects adherent to the spherically shaped adipose cells). To quantitatively confirm that the population of small cells was indeed adipose cells, we conducted a direct quantitative comparison of the cell size distributions of osmium-fixed cells prepared by tissue fixation and those prepared by fixation of isolated adipose cells derived by the flotation method from the same tissue biopsy. The graphs in Fig. 3 show that the distribution curves of the isolated cells approximate those of adipose tissue.

Table 2 presents the mean, median and mode of adipose cell diameter in the insulin-sensitive and insulin-resistant groups. While these values did not differ significantly between the two groups, the insulin-resistant group was characterised by a higher nadir $(72 \pm 13$ vs $59 \pm 10 \mu \mathrm{m}$, $p<0.01$ ) after adjusting for BMI (or waist circumference), sex and exercise), and a higher ratio of small to large cells $(1.59 \pm 0.96$ vs $0.94 \pm 0.50$, adjusted $p<0.05)$. The average peak diameter of the population of large cells was slightly larger for the insulin-resistant subjects, but the difference was small and not statistically significant.

Figure 4 shows representative adipose cell size profiles using the average parameters determined by the curvefitting analysis for the insulin-sensitive and insulin-resistant groups. MANOVA analysis applied to the curve-fit parameters showed that the overall cell size distribution was statistically significantly different ( $p=0.03$ by MANOVA) in the insulin-resistant vs insulin-sensitive group. Betweengroup comparisons of the seven individual parameters (ESM Fig. 2) showed that the peak height of the curve describing the population of large cells $\left(h_{\mathrm{p}}\right)$ was significantly lower in the insulin-resistant vs the insulin-sensitive group, even after Bonferroni's adjustment for multiple comparisons. In addition, the calculated AUC of the population of large cells (peak area) was significantly lower in the insulin-resistant subgroup than the insulin-sensitive subgroup. Similar to the raw data (Fig. 1), the fitted peak diameter of the large cells was only slightly greater in the insulin-resistant group, and the difference was not statistically significant. Thus, whether we consider the ratio of small to large cells, the height of the large-cell curve, or the
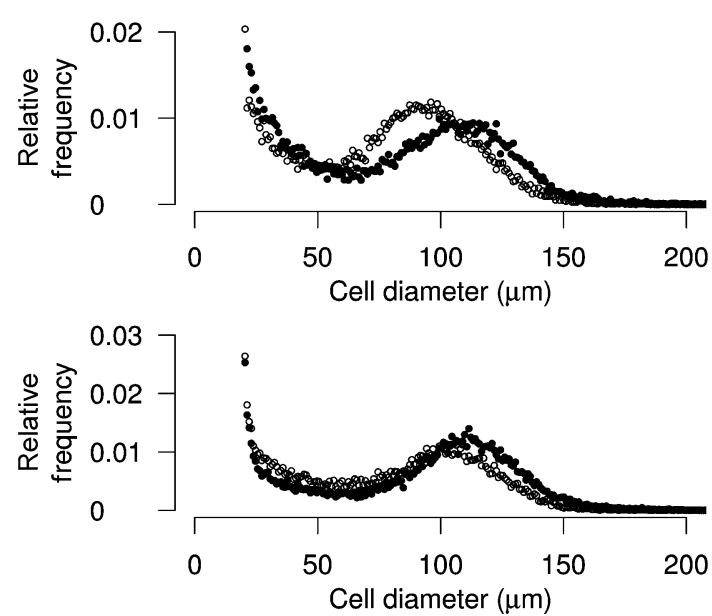

Fig. 3 Multisizer profiles of the adipose cell size distribution of biopsy samples of intact adipose tissue (open circles) and isolated adipose cells (closed circles) from the same tissue of two different subjects 
Table 2 Adipose cell size distribution in insulin-resistant vs insulin-sensitive obese individuals

\begin{tabular}{llll}
\hline & Insulin resistant $(n=13)$ & Insulin sensitive $(n=15)$ & $p$ value ${ }^{\mathrm{a}}$ \\
\hline Mean & $65 \pm 15$ & $72 \pm 8$ & 0.34 \\
Median & $59 \pm 15$ & $67 \pm 17$ & 0.42 \\
Mode & $37 \pm 35$ & $68 \pm 48$ & 0.07 \\
Nadir & $72 \pm 13$ & $59 \pm 10$ & $<0.01$ \\
Percentage of cells below the nadir & $58 \pm 11$ & $46 \pm 12$ & 0.03 \\
Ratio (small:large) & $1.59 \pm 0.96$ & $0.94 \pm 0.50$ & $<0.05$ \\
Peak diameter of large cells & $119 \pm 18$ & $115 \pm 17$ & 0.69 \\
\hline
\end{tabular}

Data are presented as means $\pm \mathrm{SD}$

${ }^{a}$ Analysis of variance adjusted for covariates: BMI $\left[\mathrm{kg} / \mathrm{m}^{2}\right]$, sex, exercise (min/week)

area under this curve, the major difference between obese individuals that are insulin resistant and those that are insulin sensitive is a lower percentage of large adipose cells and a greater percentage of small adipose cells. While both the nadir and the curve-fitting analyses are only approximate ways of separating the small and large populations, the existence of two distinct populations is visibly evident in the histograms generated from both methods.

To investigate the possibility that the small adipose cells in the insulin-resistant subjects represent relatively undifferentiated adipose cells, we measured the relative expression of genes related to adipose cell differentiation in the two subgroups (six insulin-resistant and five insulinsensitive participants). Four of the six insulin-resistant and four of the five insulin-sensitive participants were included in the cell size analysis. The demographic/metabolic characteristics of the insulin-resistant vs insulin-sensitive groups in this analysis were as follows: SSPG $12.72 \pm 2.17$ vs $3.44 \pm 0.56 \mathrm{mmol} / 1 \quad(p<0.0001)$; race (white/Asian/ Hispanic) $3 / 2 / 1$ vs $5 / 0 / 0$; sex (female/male) $3 / 3$ vs $3 / 2$; age $55 \pm 9$ vs $52 \pm 9$ years $(p=0.57)$; BMI $30.6 \pm 3.6$ vs $27.6 \pm 1.3 \mathrm{~kg} / \mathrm{m}^{2}(p=0.15)$; waist circumference $100 \pm 13 \mathrm{vs}$ $97 \pm 14 \mathrm{~cm}(\mathrm{p}=0.75)$, respectively. Table 3 demonstrates that expression of the genes encoding the differentiation factors SREBP1c, PPAR $\gamma 1$, and PPAR $\gamma 2$, and the mature

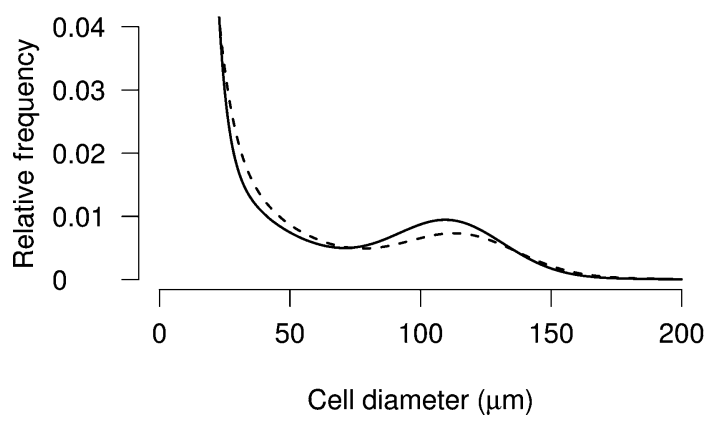

Fig. 4 Multisizer profiles of the adipose cell-size using the mean parameters from the curve-fitting formula for insulin-sensitive (solid line) and insulin-resistant (dashed line) subjects ( $p=0.03$ using MANOVA) cell proteins adiponectin and GLUT4 were all at least twofold higher in the insulin-sensitive group.

\section{Discussion}

Our results demonstrate that obese individuals harbour a complex population of adipose cells. Consistent with previous authors, we have demonstrated the presence of large subcutaneous abdominal adipose cells with diameters in the range of 100-120 $\mu \mathrm{m}$. Unlike previous authors, however, we have shown that approximately half of the adipose cells for a given volume of adipose tissue are small, in the $20-50 \mu \mathrm{m}$ range. These cells are too large to be preadipocytes or cells of haematopoietic lineage, and we confirmed the presence/relative quantity of adipose cells of this size through microscopic visualisation and Coulter Counter analysis of isolated adipose cells as compared to adipose tissue from the same individuals. Our results are contrary to our original hypothesis, that the insulin-resistant subgroup of obese individuals would harbour larger cells. Indeed, we found that the size of the large adipose cells did not differ significantly in two groups of obese individuals who represented opposite ends of the spectrum with regard to insulin resistance. Instead, we demonstrated a clear predominance of small adipose cells in the insulin-resistant subgroup, a finding that differed significantly from the insulin-sensitive subgroup, in which the large cells predominated. The expression of genes related to adipose cell differentiation was two- to threefold lower in the insulinresistant subgroup than in the insulin-sensitive subgroup, suggesting that the former subgroup is characterised by adipose cells with a lower capacity for differentiation.

We interpret these data to suggest that insulin resistance in obese individuals occurs not because they have larger adipose cells, as has previously been suggested [13, 15], but rather, at least in part, as a result of their inability to respond to the need to store excess energy (triacylglycerol) by increasing the production of fully differentiated, mature adipose cells. We found an increase in the proportion of 
Table 3 Expression of selected genes related to adipocyte terminal differentiation in the subcutaneous adipose tissue of obese insulinresistant vs insulin-sensitive subjects

\begin{tabular}{llll}
\hline Protein encoded & $\begin{array}{l}\text { Insulin resistant } \\
(n=6)\end{array}$ & $\begin{array}{l}\text { Insulin sensitive } \\
(n=5)\end{array}$ & $p$ value $^{\mathrm{a}}$ \\
\hline SREBP1c & $1.80 \pm 1.18$ & $3.57 \pm 2.14$ & 0.14 \\
PPAR $\gamma 1$ & $1.55 \pm 0.53$ & $3.30 \pm 0.43$ & $<0.01$ \\
PPAR $\gamma 2$ & $1.53 \pm 0.62$ & $3.75 \pm 1.17$ & $<0.01$ \\
Adiponectin & $1.58 \pm 0.31$ & $3.05 \pm 0.56$ & 0.001 \\
GLUT4 & $1.97 \pm 0.53$ & $6.34 \pm 2.79$ & $<0.01$ \\
Adipsin & $1.91 \pm 0.76$ & $1.54 \pm 0.29$ & 0.34 \\
\hline
\end{tabular}

${ }^{\text {a }}$ Student's unpaired $t$ test or $\chi^{2}$ test

small adipose cells, suggesting that precursor cells accumulate enough triacylglycerol to be designated adipose cells by floatation or relative size but cannot further function in the triacylglycerol storage process, consistent with observations that insulin-resistant individuals have relatively greater quantities of fat stored in their liver and skeletal muscle $[25,26]$. In addition, the relative lack of mature adipose cells could be associated with abnormalities in the secretion of terminal adipocyte-derived proteins, such as adiponectin, which coordinate adipose cell and systemic metabolism. Indeed, our findings are consistent with a prior report showing that plasma adiponectin concentrations are significantly lower in obese insulin-resistant individuals compared with similarly obese insulin-sensitive individuals [27].

At the molecular level, our findings are supported by several reports. First, it has been demonstrated in a 3T3-L1 adipocyte culture cell system that co-culture with inflammatory cytokines IL- 6 and TNF- $\alpha$ allowed early differentiation but prevented maturation to the terminal stage [28]. These dysfunctional adipocytes accumulated less triacylglycerol and expressed an inflammatory phenotype. In another report, adipose tissue from patients with HIV-1related lipoatrophy showed decreased differentiation and increased inflammation compared with controls, in association with insulin resistance [29]. We did not quantify inflammatory markers in this study, but it would be worthwhile in future investigations in human obesity to determine whether differences in cell size and/or differentiation were associated with inflammation at the molecular level, particularly as we have previously shown that several circulating inflammatory markers vary as a function of insulin sensitivity, independently of obesity [30, 31].

Our findings are also consistent with prior data in rats [32] and humans [33] showing that adipose cells can only enlarge to a finite degree in the setting of short-term overfeeding. Indeed, in both rats and humans, overfeeding led to little change in the size of large adipose cells, but resulted in an increased number of small adipose cells. Faust et al. [32] concluded that attainment of a specific mean adipose cell size triggers adipose cell proliferation or differentiation of a pool of very small and normally undetected cells. As such, in the setting of obesity and increased storage demands, if certain individuals are unable to mature a new crop of adipose cells owing to an impairment in differentiation, triacylglycerol would require storage in non-adipose tissues, as has been reported in insulin-resistant individuals [34]. In this context, our results show, for the first time, that insulin resistance in obese individuals is associated with an expanded population of small cells, and this finding differentiates them from equally obese subjects who are insulin sensitive. Indeed, these findings provide a potential explanation for the association between increasing body fat and insulin resistance, as well as the observation that not all obese individuals are insulin resistant [35].

Our results and their postulated pathophysiological consequences are consistent with human and animal lipodystrophy models, in which a near-absolute lack of subcutaneous adipose tissue is associated with insulin resistance accompanied by increased triacylglycerol deposition in muscle and liver [36, 37]. Similarly, it can be argued that the development of obesity in individuals who, for as yet unclear reasons, have a defect in their ability to increase adipose cell triacylglycerol storage by increasing the population of fully differentiated adipose cells will be more insulin resistant than equally obese individuals who have retained this ability. Our results also provide a potential explanation for the mechanism by which thiazolidenedione compounds can enhance insulin action in skeletal muscle: by stimulating adipose cell differentiation [38], the maladaptive metabolic consequences of a relative deficiency in the ability to store triacylglycerol in adipose tissue is ameliorated, with a consequent decrease in hepatic [39] and skeletal muscle fat content [40].

The methods used in this study differ from those of previous investigators who utilised either photographic techniques with measurements of adipose cell diameter and/or the technique of lipid extraction combined with cell counting of osmium-fixed cells using the more traditional Coulter Counter to estimate average cell size. If a Multisizer is used to determine how many adipose cells must be counted to obtain a reasonably accurate cell-size distribution, it can clearly be shown that most previous studies using the photographic cell sizing techniques did not analyse a sufficient number of cells. With the traditional Coulter Counter technique, instrument settings for each sample to be counted are determined by constructing a cumulative cell size curve and taking a series of counts at a plateau level that unintentionally discards the smallest cells. If only cells to the right of the nadir are considered, a single peak would be observed. These methodological differences may be responsible for the differences between our results and those of prior investigators $[15-18,41]$ who showed that insulin resistance, 
IGT, and/or hyperinsulinaemia are associated with larger mean adipose cell diameters. In view of our findings, it is clear that the 'mean' cell diameter is not sufficient to describe the population of adipose cells from a biopsy specimen.

With regard to impaired adipose cell differentiation as a potential cause of insulin resistance, our data are consistent with those of other investigators. For example, it has been shown that knocking out the gene encoding GLUT4 specifically in adipose cells is accompanied by systemic insulin resistance in vivo and skeletal muscle insulin resistance in vitro, despite the presence of a normal complement of GLUT4 in the latter tissue [42]. Studies in humans have shown the decreased expression of genes related to adipose cell differentiation in the insulinresistant offspring of patients with type 2 diabetes compared with insulin-sensitive controls [43], and the upregulation of genes related to adipose cell fat storage in response to the administration of a thiazolidenedione compound that is well known to promote increased insulin sensitivity [44]. Similar observations have been reported in Zucker $f a / f a$ rats [39]. Taken together, these prior data are consistent with our findings and strengthen the hypothesis that, in obese individuals, impairment in adipose cell differentiation is characterised by a relative reduction in large adipose cells and an abundance of small adipose cells. The resulting decreased ability to store triacylglycerol in subcutaneous adipose tissue is likely an important contributor to the development of skeletal muscle insulin resistance.

Our study is limited by its small size. Furthermore, we cannot prove causality but merely report associations in this human study. Note that we are not claiming that small cells differ from large cells with respect to gene expression and fat metabolism. Rather, we are proposing that differences exist between adipose cells in insulin-sensitive and insulinresistant subjects that are associated with a quantifiable difference in cell size distribution. Additional metabolic differences may exist between small and large cells that could contribute to the impact on whole-body metabolism of the differences in cell size distributions, but such a determination would require further work to separate the cells by size.

We adjusted for possible confounding effects of slight differences in BMI and waist circumference, as well as sex and exercise. Our study subjects were primarily white, and thus our results may not be generalisable to all racial groups. Finally, because the participants in our study were only available for subcutaneous adipose tissue biopsy, we could not assess the contribution of visceral adipose tissue to insulin resistance. However, parallel studies in rodents have shown that similar adipose cell size distributions apply across depots (D.G. Hunt, X. Chen, M. Santos, N. Tserentsoodol, S. Cushman; unpublished results). Strengths include the characterisation of two similarly obese groups who differed metabolically, and the use of newer technology to characterise cell size distribution in a more sophisticated manner.
In conclusion, our findings point to a primary defect in the adipose cell that relates to the development of insulin resistance in obese individuals. The findings of an enhanced population of small adipose cells and the decreased expression of genes related to adipose cell differentiation, strongly suggest that variation in adipose cell characteristics that are independent of, but likely interactive with obesity, play a major role in the development of insulin resistance. Specifically, our findings suggest that, in the setting of obesity, individuals who are unable to recruit an additional population of mature adipose cells for triacylglycerol storage will develop insulin resistance. In an era of increasing body weight, which is not likely to soon reverse, our findings highlight the need to focus on adipose cells/tissue as a potential mediator of insulin resistance. Follow-up studies that clarify the mechanisms by which differentiation of adipose cells is impaired, and the cellular and metabolic response of adipose cells to targeted interventions that can alter insulin resistance are necessary. Such studies may eventually lead to novel techniques for risk stratification and/or novel therapeutic targets for intervention in those patients at highest risk for obesityassociated complications.

Acknowledgements The authors would like to acknowledge the following individuals: N. Tserentsoodol (formerly NIDDK, now National Eye Institute, NIH, Bethesda, MD, USA), for performing light microscopy on our adipose tissue biopsy samples; J. Kosek (Department of Pathology, Palo Alto Veterans' Hospital, Palo Alto, CA, USA), for performing scanning electron microscopy of our adipose tissue samples; U. Smith (Lundberg Laboratory for Diabetes Research, Gothenburg University Medical Center, Gothenburg, Sweden), for performing adipose tissue, isolated adipose cell comparisons; L. B. Salans (Clinical Professor of Medicine, Mount Sinai Medical Center and Adjunct Professor of Medicine, College of Physicians and Surgeons, Columbia University, New York, NY, USA), for intellectual support of this study idea; D. Kahn (Department of Surgery, Stanford University, Stanford, CA, USA) for assistance with developing adipose tissue biopsy techniques; and V. Periwal (Laboratory of Biological Modeling, NIDDK) and R. Wesley (Warren Grant Magnuson Clinical Center, NIH, Bethesda, MD, USA), for discussions of statistical analysis. Funding for this study was provided by study grants NIH/NIDDK 1 R01 DK071309-01, 5K23 RR16071, and NIH RR 000070, and by the NIDDK Intramural Research Program.

Duality of interest statement There are no dualities of interest on the part of the authors.

\section{References}

1. Rabinowitz D, Zierler KL (1962) Forearm metabolism in obesity and its response to intra-arterial insulin. Characterization of insulin resistance and evidence of adaptive hyperinsulinemia. J Clin Invest 41:2173-2181

2. Olefsky J, Reaven GM, Farquhar JW (1974) Effects of weight reduction on obesity. Studies of lipid and carbohydrate metabolism in normal and hyperlipoproteinemic subjects. J Clin Invest 53:64-76 
3. DeFronzo RA, Soman V, Sherwin RS, Hendler R, Felig P (1978) Insulin binding to monoctyes and insulin action in human obesity, starvation, and refeeding. J Clin Invest 62:204-213

4. Kolterman OG, Insel J, Saekow M, Olefsky JM (1980) Mechanisms of insulin resistance in human obesity. Evidence for receptor and postreceptor defects. J Clin Invest 65:1272-1284

5. Bjorntorp P, Sjostrom L (1978) Carbohydrate storage in man: speculations and some quantitative considerations. Metabolism 12 (Suppl 2):1853-1865

6. DeFronzo RA, Ferannini E, Hendler R, Wahren J, Felig P (1978) Influence of hyperinsulinemia, hyperglycemia, and the route of glucose administration on splanchnic glucose exchange. Proc Natl Acad Sci USA 75:5173-5177

7. McLaughlin T, Abbasi F, Carantoni M, Schaaf P, Reaven GM (1999) Differences in insulin resistance do not predict weight loss in response to hypocaloric diets in healthy obese women. J Clin Endocrinol Metab 84:578-581

8. Jones CN, Abbasi F, Carantoni M, Polonsky KS, Reaven GM (2000) Roles of insulin resistance and obesity in regulation of plasma insulin concentrations. Am J Physiol Endocrinol Metab 278:E501-E508

9. Abbasi F, Brown BWB, Lamendola C, McLaughlin T, Reaven GM (2002) Relationship between obesity, insulin resistance, and coronary heart disease risk. J Am Coll Cardiol 40:937-943

10. McLaughlin T, Abbasi F, Lamendola C et al (2002) Differentiation between obesity and insulin resistance in the association with C-reactive protein. Circulation 106:2908-2912

11. Kissebah AH, Vydelingum N, Murray R et al (1981) Relation of body fat distribution to metabolic complications of obesity. J Clin Endocrinol Metab 54:254-260

12. Krotkiewski M, Bjorntop P, Sjostrom L, Smith U (1983) Impact of obesity on metabolism in men and women: importance of regional adipose tissue distribution. J Clin Invest 72:1150-1162

13. Salans LB, Knittle JL, Hirsch J (1968) Role of adipose cell size and adipose tissue insulin sensitivity in the carbohydrate intolerance of human obesity. J Clin Invest 47:152-165

14. Hirsch J, Knittel JL (1970) Cellularity of obese and non-obese human adipose tissue. Fed Proc 29:1516-1521

15. Stern JS, Batchelor BR, Hollander N, Cohn CK, Hirsch J (1972) Adipose cell size and immunoreactive insulin levels in obese and normal weight adults. Lancet 2:948-951

16. Brook CG, Lloyd JK (1973) Adipose cell size and glucose tolerance in obese children and effect of diet. Arch Dis Child 48:301-304

17. Salans LB, Cushman SW, Weismann RE (1973) Studies of human adipose tissue: adipose cell size and number in non-obese and obese patients. J Clin Invest 52:929-941

18. Foley JE, Lillioja S, Zawadzki J, Reaven GM (1986) Comparison of glucose metabolism in adipocytes from Pima Indians and Caucasians. Metabolism 35:193-195

19. Pei D, Jones CNO, Bhargava R, Chen Y-DI, Reaven GM (1994) Evaluation of octreotide to assess insulin-mediated glucose disposal by the insulin suppression test. Diabetologia 37:843-845

20. Shen S-W, Reaven GM, Farquhar JW (1970) Comparison of impedance to insulin mediated glucose uptake in normal and diabetic subjects. J Clin Invest 49:2151-2160

21. Greenfield MS, Doberne L, Kraemer FB, Tobey TA, Reaven GM (1981) Assessment of insulin resistance with the insulin suppression test and the euglycemic clamp. Diabetes 30:387-392

22. Yeni-Komshian H, Carantoni M, Abbasi F, Reaven GM (2000) Relationship between several surrogate estimates of insulin resistance and quantification of insulin-mediated glucose disposal in 490 healthy, nondiabetic volunteers. Diabetes Care 23:171-175

23. Carantoni M, Abbasi F, Chu L et al (1997) Adherence of mononuclear cells to endothelium in vitro is increased in patients with NIDDM. Diabetes Care 20:1462-1465
24. Rodbell M (1964) Metabolism of isolated fat cells. I. Effects of hormones on glucose metabolism and lipolysis. J Biol Chem 239:375-380

25. Danforth E (2000) Failure of adipocyte differentiation causes type II diabetes mellitus? Nat Genet 26:13

26. Heilbronn L, Smith SR, Ravussin E (2004) Failure of fat cell proliferation, mitochondrial function and fat oxidation results in ectopic fat storage, insulin resistance and type II diabetes mellitus. Int J Obes 28:512-521

27. Abbasi F, Chu JW, Lamendola C, McLaughlin T, Hayden J, Reaven GM, Reaven PD (2004) Discrimination between obesity and insulin resistance in the relationship with adiponectin. Diabetes 53:585-590

28. Gustafson B, Smith U (2006) Cytokines promote Wnt signaling and inflammation and impair the normal differentiation and lipid accumulation in 3T3-L1 preadipocytes. J Biol Chem 281:9507-9516

29. Jan V, Cervera P, Maachi M et al (2004) Altered fat differentiation and adipocytokine expression are inter-related and linked to morphological changes and insulin resistance in HIV-1-infected lipodystrophic patients. Antivir Ther 9:555-564

30. McLaughlin T, Abbasi F, Lamendola C et al (2002) Differentiation between obesity and insulin resistance in the association with C-reactive protein. Circulation 106:2908-2912

31. Zavaroni I, Gasparini P, Barilli AI et al (2000) Comparison of fasting plasma leptin concentrations in healthy subjects with high and low plasma insulin. Metabolism 49:499-502

32. Faust IM, Johnson PR, Stern JS, Hirsch J (1978) Diet-induced adipocyte number increase in adult rats: a new model of obesity. Am J Physiol 4:E279-E286

33. Kashiwagi A, Mott D, Bogardus C, Lillioja S, Reaven GM, Foley JE (1985) The effects of short-term overfeeding on adipocyte metabolism in Pima Indians. Metabolism 34:364-370

34. Savage DM, Petersen KF, Shulman GI (2005) Mechanisms of insulin resistance in humans and possible links with inflammation. Hypertension 45:828-833

35. McLaughlin T, Allison G, Abbasi F, Lamendola C, Reaven G (2004) Prevalence of insulin resistance and associated cardiovascular disease risk factors among normal weight, overweight, and obese individuals. Metabolism 53:495-499

36. Garg A (2000) Lipodystrophies. Am J Med 108:143-152

37. Kim JK, Gavrilova O, Chen Y, Reitman ML, Shulman GI (2000) Mechanism of insulin resistance in A-ZIP/F-1 fatless mice. J Biol Chem 24(275):8456-8460

38. Hallakou S, Doare L, Foufelle F et al (1997) Pioglitazone induces in vivo adipocyte differentiation in the obese Zucker fa/fa rat. Diabetes 46:1393-1399

39. Weyer C, Foley JE, Bogardus C, Tataranni PA, Pratley RE (2000) Enlarged subcutaneous abdominal adipocyte size, but not obesity itself, predicts type II diabetes independent of insulin resistance. Diabetolologia 43:1498-1506

40. Boden G, Cheung P, Mozzoli M, Fried SK (2003) Effect of thiazolidinediones on glucose and fatty acid metabolism in patients with type 2 diabetes. Metabolism 52:753-759

41. Goodpasteur BH, Thaete FL, Kelley DE (2000) Thigh adipose tissue distribution is associated with insulin resistance in obesity and in type 2 diabetes mellitus. Am J Clin Nutr 71:885-892

42. Abel ED, Peroni O, Kim JK et al (2001) Adipose-selective targeting of the GLUT4 gene impairs insulin action in muscle and liver. Nature 409:729-733

43. Yang X, Jansson PS, Nagaev I et al (2004) Evidence of impaired adipogenesis in insulin resistance. Biochem Biophys Res Commun 317:1045-1051

44. Bogacka I, Xie H, Bray GA, Smith SR (2004) The effect of pioglitazone on peroxisome proliferator-activated receptor-target genes related to lipid storage in vivo. Diabetes Care 27:1660-1667 